1 Prevalence, risk factors and genotype distribution of Toxoplasma gondii DNA in soil in

\title{
2 China
}

3

4 Wei Cong ${ }^{\mathrm{a}, *}$, Nian-Zhang Zhang ${ }^{\mathrm{b}}$, Rui-Si Hu${ }^{\mathrm{b}}$, Feng-Cai Zou ${ }^{\mathrm{c}}$, Yang Zou ${ }^{\mathrm{b}}$, Wen-Yan 5 Zhong ${ }^{\mathrm{d}}$, Jing-Jing $\mathrm{Wu}^{\mathrm{d}}$, Christopher J. Fallaize ${ }^{\mathrm{e}, \mathrm{f}}$, Xing-Quan Zhu ${ }^{\mathrm{b}}$, Hany M. Elsheikha ${ }^{\mathrm{f}, * *}$ 6

7 a Marine College, Shandong University at Weihai, Weihai, Shandong Province, PR China

8 b State Key Laboratory of Veterinary Etiological Biology, Key Laboratory of Veterinary Parasitology of

9 Gansu Province, Lanzhou Veterinary Research Institute, Chinese Academy of Agricultural Sciences,

10 Lanzhou, Gansu Province, PR China

$11 \mathrm{c}$ College of Veterinary Medicine, Yunnan Agricultural University, Kunming, Yunnan Province, 650201,

12 PR China

$13 \mathrm{~d}$ Department of Mathematics and Statistics, University of Calgary, Calgary, Alberta, Canada

14 e School of Mathematical Sciences, University of Nottingham, Nottingham, United Kingdom

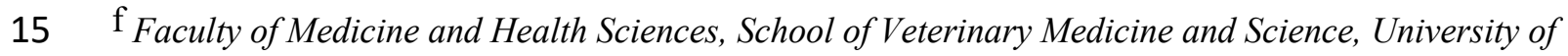

16 Nottingham, Sutton Bonington Campus, Loughborough, United Kingdom

\section{*Correspondence:}

20 Wei Cong

21 messicw@163.com

22 Hany M. Elsheikha

23 hany.elsheikha@nottingham.ac.uk 


\section{ABSTRACT}

In the present study, we performed a cross-sectional survey to determine the occurrence and genotype distribution of $T$. gondii DNA in soil samples collected from different sources from six geographic regions in China. Between March 2015 and June 2017, 2100 soil samples were collected from schools, parks, farms and coastal beaches, and examined for T. gondii DNA using three PCR assays targeting 529-bp repeat element (RE) sequence, B1 gene and ITS-1 gene sequences. Also, we investigated whether geographic region, soil source and type, and sampling season can influence the prevalence of $T$. gondii DNA in the soil. Soil samples collected from farms and parks had the highest prevalence, whereas samples collected from school playgrounds and coastal beaches had the lowest prevalence. PCR assays targeting 529bp RE and ITS-1 gene sequences were more sensitive than the B1 gene-based assay. Positive PCR products were genotyped using multi-locus PCR-RFLP, and ToxoDB \#9 was the predominant genotype found in the contaminated soil samples. Multiple logistic regression identified factors correlated significantly with the presence of $T$. gondii DNA in the soil to be the source of the soil, including farms (odds ratio 3.10; 95\% confidence interval [CI], 1.52 to $6.29 ; p=0.002)$ and parks $(2.59 ; 95 \%$ CI 1.28 to $5.27 ; p=0.009)$. These results show that Chinese soil hosts $T$. gondii of the most prevalent genotype in China (ToxoDB\#9) and that the soil type influences infection patterns.

\section{Keywords: Soil contamination; Toxoplasma gondii; Prevalence; Genotypes; China}

\section{Introduction}

Toxoplasmosis is a zoonotic disease caused by the protozoan Toxoplasma gondii, which is capable of infecting a wide range of avian and mammalian species (Montoya and Liesenfeld, 2004; Dubey and Beattie, 2010). Toxoplasmosis can cause serious illness and even death in congenitally infected infants and immunocompromised patients (Dubey and Beattie, 2010). This disease can also cause economic losses attributed to abortion and stillbirth in sheep and goats (Dubey and Beattie, 2010; Robert-Gangneux and Dardé, 2012). In addition to con- genital transmission, $T$. gondii is a foodborne and waterborne pathogen, which often leads to human infection through the consumption of un- dercooked meat containing parasite cysts, or by ingestion of food or water contaminated with sporulated oocysts (Frenkel et al., 1970).

Soil-borne toxoplasmosis has been reported in many countries, such as USA and Brazil (Stagno et al., 1980; Coutinho et al., 1982), high- lighting the importance of avoiding accidental ingestion of these en- vironmentally resistant oocysts (Alvarado-Esquivel et al., 2010; Dabritz and Conrad, 2010). Although T. gondii oocysts spread in the environ- ment is an important source of toxoplasmosis to humans and animals, little is known about the level of soil contamination with oocysts and how prevalence varies across soil types in China.

Understanding the ecology of $T$. gondii in the soil can inform our environmental and public health policy. In order to understand the factors contributing to oocyst adaptation and survival in soil, an asso- ciation between the variables that influence the distribution of $T$. gondii oocysts in soil, such as soil heterogeneity and climatic conditions, is required. Despite the availability of some tools that can be used for the detection of $T$. gondii oocysts in the soil (Dubey and 
Beattie, 2010; Dubey, 2010; Jones and Dubey, 2010; Salant et al., 2010), the pre- valence of oocysts in the soil remains poorly defined (Afonso et al., 2008; Lass et al., 2009; Dos Santos et al., 2010).

The objectives of this study were to (i) identify $T$. gondii oocyst's DNA in soil samples and compare infection prevalence and genotype distribution in six different geographic regions in China and (ii) identify the possible risk factors associated with soil contamination with $T$. gondii oocyst's DNA. Comparative analysis of the soil samples was performed using three PCR-based assays, targeting 529-bp RE, B1 gene and ITS-1 region of rDNA gene, for the detection of $T$. gondii oocyst DNA in soil samples. The study shows that $10.9 \%$ of the tested soil samples from various regions in China contained $T$. gondii DNA, which may pose a risk to humans.

\section{Materials and methods}

\subsection{Study sites}

This study was performed in six provinces in China, including Shandong (Eastern), Henan (Centeral), Jilin (northeastern), Gansu (Northwestern), Yunnan (Southwestern), and Guangdong (Southern). Data about the climatic conditions of the studied regions were obtained from the local government website of each province. Shandong province $\left(34^{\circ} 23^{\prime} \sim 38^{\circ} 24^{\prime} \mathrm{N}\right.$, $114^{\circ} 48^{\prime} \sim 122^{\circ} 42^{\prime} \mathrm{E}$ ) has warm temperate monsoon climate, with an annual average temperature of $11{ }^{\circ} \mathrm{C}-14{ }^{\circ} \mathrm{C}$ and an average illumination of 2290-2890 h. Average annual rainfall ranges between 550 and $950 \mathrm{~mm}$, with an annual precipitation of $60 \%-70 \%$, concentrated in the summer. Henan province $\left(31^{\circ} 23^{\prime} \sim 36^{\circ} 22^{\prime} \mathrm{N}, 110^{\circ} 21^{\prime} \sim 116^{\circ} 39^{\prime} \mathrm{E}\right)$ has warm temperate to subtropical, humid to semi-humid monsoon climate. The annual average temperature ranges between $12{ }^{\circ} \mathrm{C}$ and $16^{\circ} \mathrm{C}$. Average annual rainfall is between 500 and $900 \mathrm{~mm}$, and the annual precipitation is $50 \%$, concentrated in the summer. Jilin province $\left(40^{\circ} 50^{\circ} \sim 46^{\circ} 19^{\prime} \mathrm{N}\right.$, $\left.121^{\circ} 38^{\prime} \sim 131^{\circ} 19^{\prime} \mathrm{E}\right)$ has temperate monsoon climate. This province has an average temperature of $-11^{\circ} \mathrm{C}$ in the winter, whereas in the summer the average temperature is $23{ }^{\circ} \mathrm{C}$. Average annual rainfall is between 400 and $600 \mathrm{~mm}$, and the annual precipitation is $80 \%$, concentrated in the summer. Gansu province $\left(32^{\circ} 31^{\prime} \sim 42^{\circ} 57^{\prime} \mathrm{N}, 92^{\circ} 13^{\prime} \sim 108^{\circ} 46^{\prime} \mathrm{E}\right)$ has temperate continental monsoon climate. The annual average temperature is between $0{ }^{\circ} \mathrm{C}$ and $16^{\circ} \mathrm{C}$. Average annual rainfall is between 36.6 and $734.9 \mathrm{~mm}$, and the annual precipitation is $50 \%-70 \%$ concentrated between June and August. Yunnan province $\left(21^{\circ} 8^{\prime} \sim 29^{\circ} 15^{\prime} \mathrm{N}, 97^{\circ} 31^{\prime} \sim 106^{\circ} 11^{\prime} \mathrm{E}\right)$ has tropical monsoon to subtropical monsoon climate. In the hottest month (July), the temperature ranges from $19{ }^{\circ} \mathrm{C}$ to $22{ }^{\circ} \mathrm{C}$, in the coldest month (January) temperature is about $6{ }^{\circ} \mathrm{C}-8{ }^{\circ} \mathrm{C}$. The distribution of precipitation in this province varies by season and region. Guangdong province $\left(20^{\circ} 13^{\prime} \sim 25^{\circ} 31^{\prime} \mathrm{N}, 109^{\circ} 39^{\prime} \sim 117^{\circ} 19^{\prime} \mathrm{E}\right)$ has subtropical monsoon climate. The annual average temperature is between $19{ }^{\circ} \mathrm{C}$ and $24{ }^{\circ} \mathrm{C}$ and the average annual rainfall is between 1300 and $2500 \mathrm{~mm}$.

\subsection{Soil sampling}

From March 2015 to June 2017, a total of 420 soil sampling spots were examined. These included sampling spots from 20 schools, 20 parks and 20 farms from each of the six provinces (i.e. 360 sampling spots), in addition to sampling from 60 coastal beaches in Shandong 
province. From each sampling spot $\left(\sim 10 \mathrm{~m}^{2}\right)$, five soil samples from five randomly selected locations within each sampling spot were collected (i.e, a total of 2100 samples). Each soil sample of $20 \mathrm{~g}$ was collected $5 \mathrm{~cm}$ below the soil's surface using stainless steel scoops, airdried, and passed through 20-mesh sieve (Du et al., 2012). The types of soil sample surveyed included brown soil, yellow brown soil, dark brown forest soil, chernozem (black-coloured soil), fine sand, coarse sand, red soil, latosolic red soil, and yellow cinnamon soil.

\subsection{DNA extraction and PCR assays}

Oocysts present in the soil samples were purified as described previously (Lélu et al., 2012). Isolation of oocyst DNA from the soil samples was carried out using E. Z.N.A. ${ }^{\text {TM }}$ Soil DNA Kit (OMEGA, USA), following the manufacturer's recommendations. Extracted DNA was stored at $-20^{\circ} \mathrm{C}$ until use. The presence of $T$. gondii DNA was examined by conventional, seminested and nested PCR assays that targeted a 529bp-repeat element (RE), a 98bp fragment of B1 gene and a 227bp fragment of the multicopy internal transcribed spacer-1 (ITS-1) region of rDNA, as described previously (Homan et al., 2000; Jones et al., 2000; Burrells et al., 2013). The three assays were run in triplicate and included negative (without DNA) and positive (DNA extracted from tachyzoites of $T$. gondii RH strain genotype I) controls. The primers used in the three PCR assays are listed in the Supplementary Table S1.

\subsection{Genotyping of T. gondii}

Positive PCR products were subjected to further genetic characterization. Genotyping was carried out using PCR-restriction fragment length polymorphism (PCR-RFLP) analysis of 11 genes and sequences - SAG1, SAG2, alter. SAG2, SAG3, BTUB, GRA6, c22-8, L358, c29-2, PK1, and Apico - previously used as markers for T. gondii genotypic dis- crimination (Cong et al., 2015, 2017). Nine reference T. gondii strains, GT1, PTG, CTG, MAS, TgCgCa1, TgCatBr5, TgWtdSc40, TgCatBr64, and TgToucan, were included as positive controls. PCRs were performed in $25-\mu 1$ volumes. Each reaction was set up using $1 \times$ PCR buffer, $0.2 \mu \mathrm{M}$ of each primer, $200 \mu \mathrm{M}$ deoxynucleoside triphosphates (dNTPs), $2 \mathrm{mM} \mathrm{MgCl} 2,0.2 \mathrm{U}$ of HotStartTaq DNA polymerase (TAKARA, Japan). The PCR products were amplified using a thermal cycler (PTC 200, Bio- RAD) under the following conditions: $95^{\circ} \mathrm{C}$ for $5 \mathrm{~min}$ to activate the DNA polymerase, followed by 30 cycles of $95{ }^{\circ} \mathrm{C}$ for $30 \mathrm{~s}, 55^{\circ} \mathrm{C}$ for $60 \mathrm{~s}$, and $72{ }^{\circ} \mathrm{C}$ for $90 \mathrm{~s}$, and a final extension at $72{ }^{\circ} \mathrm{C}$ for $10 \mathrm{~min}$. Multiplex PCR-amplified products were diluted 1:1 in sterile, double-distilled water, and used for nested PCR amplification with internal primers for each marker, separately. A similar amplification program was used for the nested PCR. The nested PCR amplifications were carried out with an annealing temperature of $60^{\circ} \mathrm{C}$ for $60 \mathrm{~s}$ for all the markers except Apico, which was amplified at $55^{\circ} \mathrm{C}$. The nested PCR products were digested with restriction enzymes for $1 \mathrm{~h}$, but the temperature for each enzyme was used as per the manufacturer's instructions. The restriction fragments were resolved on $2 \%$ agarose gels, visualized by GoldenViewTM and photographed using a gel documentation system (UVP GelDoc- ItTM Imaging System, Cambridge, U.K.). Details of the oligonucleotide primers used in the Mutiplex PCR and nested PCR are shown in Table S2 and Table S3, respectively.

\subsection{Statistical analysis}


Associations between categorical variables were analyzed by Chi- square test. $P$ values < 0.05 were considered to represent statistical significance. Univariate logistic regression was performed to determine associations between the presence of $T$. gondii DNA in the soil and various factors, such as soil source, soil type, geographic region, season, and climatic features. Multiple logistic regression (using generalized linear mixed models) was carried out to determine which of the variables, when all of them are considered in combination, explain the observed variation in prevalence of $T$. gondii DNA. To account for correlation between the samples collected at each of the 420 sites, the sampling site was included as a random effect. Although multiple sites were sampled in each region, there are only six regions and their potential effects are of intrinsic interest, so sampling region was considered as a fixed effect. However, this was found to be non-significant. Hence, the grouping structure in the random effects part of the model was by sampling site only. Odds ratios (ORs) and their $95 \%$ confidence intervals ( $95 \%$ CIs) for the effects of the different levels of significant was performed using statistical software R (Version 3.4.4; http://www. R-project.org) (R Development Core Team, 2011). The generalized linear mixed models were fitted using penalized quasi-likelihood using routines from the R library MASS (Venables and Ripley, 2002).

\section{Results}

\subsection{Contamination levels of T. gondii DNA in the soil}

The prevalence of $T$. gondii DNA in 2100 soil samples from six provinces in China was determined. As shown in Table 1, 230 PCR positive T. gondii DNA samples were detected amounting to $10.9 \%$ overall prevalence of $T$. gondii DNA in all soil samples. The prevalence of $T$. gondii DNA detected in the individually tested samples ranged from $4.3 \%$ in high school playground to $16 \%$ in poultry farms (Table 1 ). Soil samples collected from farms (poultry [16\%] and livestock [14.7\%]) and parks (comprehensive [15\%] and residential [14.7\%]) had the highest prevalence with $T$. gondii DNA (Table 1). The lowest prevalence was detected in samples collected from school playgrounds (high school [4.3\%] and elementary school [5.3\%]) and coastal beach $(6.7 \%)$.

Out of the 420 sampled sites, 136 were positive, meaning that $32.3 \%$ of the tested sites were contaminated by $T$. gondii DNA (Table 2). Considering all types of the 420 sampling sites, the proportion of soil samples tested positive for $T$. gondii DNA ranged from $21.7 \%$ in high school playground to $55 \%$ in residential park. Again, farms (livestock [41.6\% 6 ] and poultry [40\%]) and parks (residential park [55\%] and comprehensive [35\%]) had the highest prevalence of contamination with $T$. gondii DNA (Table 2). Samples collected from school play- grounds (high school $[21.7 \%]$ and elementary [23.3\%]) and coastal beach (20\%), had the lowest prevalence (Table 2).

\subsection{Factors influencing T. gondii prevalence in soil}

According to univariate logistic regression analysis, we identified the following risk factors for the presence of $T$. gondii oocysts in soil: costal beach (odds ratio, 14; 95\% confidence interval [CI], 9.14 to $22.76 ; p<2 \mathrm{e}-16)$, geographic region Gansu (8.37; $95 \%$ CI, 5.90 to 12.31 ; $p<2 \mathrm{e}-16)$, autumn season $(5.81 ; 95 \% \mathrm{CI}, 4.51$ to $7.61 ; p<2 \mathrm{e}-16)$, brown soil $(7.82 ; 95 \% \mathrm{CI}$, 5.55 to $11.37 ; \mathrm{p}<2 \mathrm{e}-16)$; and subtropical monsoon climate $(8.67 ; 95 \% \mathrm{CI}, 6.08$ to $12.83 ; p<$ 
2e-16) (Table S4). Multiple logistic regression analysis identified soil source as the only significant factor influencing the presence of $T$. gondii. The reference level for soil source is "coastal beach" and the odds ratios relative to this reference level found to be statistically significant is: soil source farm $(3.10 ; 95 \%$ CI 1.52 to $6.29 ; p=0.002)$ and soil source park (2.59; 95\% CI 1.28 to $5.27 ; p=0.009$ ) (Table 3 ). Therefore, for ex- ample, we estimate that a soil source farm increases the odds ratio of presence of $T$. gondii DNA by a factor of 3.10 over that of coastal beach. Logistic regression analysis was also performed on the results obtained by individual PCR assays, and similar conclusions were obtained.

\subsection{PCR-RFLP analysis}

We compared the effectiveness of three different PCR assays targeting the sequences of 529bp RE sequence, B1 gene and ITS-1 region of rDNA gene. Out of 2100 soil samples, amplification products were obtained from 179, 212 and 207 specimens using B1 gene, 529-bp RE and ITS-1 region of rDNA gene, respectively. Of these, 156 samples yielded amplification products using the three PCR assays, 10 samples were positive by 529-bp RE-based PCR assay, one sample was positive by B1 gene-(semi) nested PCR assay, and 9 samples were positive by ITS-1-nested PCR assay. The comparative performance of the three PCR assays in terms of detecting oocysts in soil samples is shown (Supplementary Fig. 1). Out of the 231 positive soil samples, 15 samples were successfully genotyped by PCR-RFLP and had restriction digest profiles consistent with that of the most prevalent Chinese T. gondii genotype ToxoDB\#9 (Table 4).

\section{Discussion}

Better understanding of how environmental factors may influence the prevalence and genotype distribution of $T$. gondii DNA in the soil is essential for identification, assessment and management of the health and safety risks faced by members of the public. In the present study, we found that 29 (4.8\%) out of 600 soil samples from public schools were positive for T. gondii DNA. This prevalence is less that reported in a previous report, where $15(14.15 \%)$ out of 106 soil samples were found contaminated with $T$. gondii oocysts from schools in Lanzhou (capital city of Gansu province), northwest China using PCR method based on the 529-bp RE sequence (Wang et al., 2014). Also, 50\% (60/ 120) of the soil samples examined from the parks in the present study were contaminated by $T$. gondii DNA. These findings support results obtained previously where $T$. gondii oocysts were found widely distributed in soil samples of public parks in Wuhan (Du et al., 2012) and Lanzhou (Wang et al., 2014) in China.

The presence of such high levels of $T$. gondii DNA contamination in the soil samples obtained from the playground of schools and parks is worrying because these areas have become an increasingly important in the outdoor activities of the people in China; for the elderly to work out and for the children to play. Various factors can influence the level of soil contamination with $T$. gondii DNA, such as the density of the felid definitive host, hygienic standards implemented in the parks and schools, and climatic conditions (Dumètre and Dardé, 2003; Afonso et al., 2008; Meerburg and Kijlstra, 2009; Gotteland et al., 2014). Cats play a key role in the transmission of $T$. gondii by depositing oocysts into the soil with their feces. Catderived oocysts persist in the environment for long periods (Dumètre and Dardé, 2003; Dubey 
and Beattie, 2010; Dubey, 2010) and can contaminate the estuarial water through surface runoff and soil washing. Given that cat-soil-intermediate host cycle presents a common mechanism by which $T$. gondii can reach new hosts, public health authorities should consider investigating the correlation between the presence of cats and the burden of $T$. gondii oocyst's contamination in the playground of schools and public parks.

The factors contributing to the flux of $T$. gondii oocysts into coastal waters have received some attention in the literature (Shapiro et al., 2010; Simon et al., 2013a,b). Anthropogenic changes (human-induced alterations in the coastal landscape and destruction of wetland habitats) and climate change (e.g. rising sea level, flooding and surface runoff) are among some of the mechanisms contributing to the contamination of nearshore waters with terrestrially derived zoonotic pathogens (Jones et al., 2008; Shapiro et al., 2010; Simon et al., 2013a,b; VanWormer et al., 2016). In the present study, we found evidence for high prevalence $(20 \%)$ of $T$. gondii oocysts in soil samples from coastal/ bathing beaches (Table 2). T. gondii oocysts kept in seawater $(15 \mathrm{ppt} \mathrm{NaCl})$ at $4{ }^{\circ} \mathrm{C}$ for 24 months maintained their infectivity to mice (Lindsay and Dubey, 2009). Therefore, increased prevalence of $T$. gondii oocyst DNA contamination in coastal beaches highlights the potential contamination of nearshore waters with this terrestrially derived, water-borne zoonotic parasite and the subsequent increase in human exposure to $T$. gondii infection through recreation activities or consumption of seafood harvest (Jones et al., 2008, 2009; Simon et al., 2013a,b; VanWormer et al., 2016).

Animal farms have been considered as hotspot areas for the trans- mission risk of $T$. gondii oocyst infection in rural environments (Gotteland et al., 2014; Simon et al., 2017). In agreement with these studies, our data (Table 2) showed that soil samples from $58.3 \%$ of livestock farms and $46.7 \%$ of poultry farms are contaminated with $T$. gondii DNA. Other variables, such as the climatic feature subtropical monsoon and the autumn season also seem to influence the occurrence of $T$. gondii oocysts in soil in the present study (Table S4). The effect of spring conditions on the fate and dispersion of $T$. gondii oocysts from the melting snowpack to the Canadian arctic coast via the freshwater runoff has been appreciated (Simon et al., 2013a,b). More prevalence was detected in Gansu province and brown soil (Table S4), suggesting that geographic region and soil types are potential risk factors for soil contamination with $T$. gondii oocysts. Gansu province is characterized by a temperate continental monsoon climate with an annual average temperature between $0{ }^{\circ} \mathrm{C}$ and $16^{\circ} \mathrm{C}$. T. gondii oocysts seem to have a better survival rate at $4{ }^{\circ} \mathrm{C}$ compared to ambient temperature (Lindsay and Dubey, 2009; Gagelidze et al., 2018). The reason for the high as- sociation between brown soil and occurrence of oocysts in our study might be related to the possibility that soil type (brown soil) could also be linked to soil source (e.g. farm), however the exact reasons remain to be determined.

Currently, there is lack of knowledge on the nature or extent of any effect of soil type on $T$. gondii oocyst survival. A recent survey of 18 types of soils of Georgia has shown that the total number of bacteria and frequency of occurrence of certain bacterial genera vary by soil type ( $\mathrm{Li}$ et al., 2015). The physical, chemical and biological parameters of the soil can vary with soil type and sampling season. Hence, knowledge of soil parameters that may influence the survival of $T$. gondii oocysts within soil is important for the development of risk assessment and management strategies aimed at reducing public health risks from activities such as land application of wastes containing human pathogens. 
A few PCR-based methods have been developed for detection of $T$. gondii oocyst DNA (Salant et al., 2010; Mancianti et al., 2015; Chemoh et al., 2016; Liu et al., 2017). Of these, PCR assays targeting highly conserved repetitive DNA sequences, such as B1 gene, 529-bp repeat element (RE) and internal transcribed spacer-1 (ITS-1) region of ribo- somal DNA gene, seem to have good sensitivities (Salant et al., 2007, 2010; Chemoh et al., 2016). Other detection methods such as microscopy can not discern between oocysts of $T$. gondii and oocysts of other coccidian species due to the similarities between their morophological features. To our knowledge, this is the first study to analyze soil samples using, simultaneously, three PCR assays based on the amplification of 529-bp RE sequence, B1 gene and ITS-1 region of rDNA gene sequences.

A previous study comparing the prevalence of $T$. gondii DNA in cat feces using PCR assays targeting 529-bp RE sequence and ITS-1 gene showed that amplification based on ITS-1 gene was approximately seven times more sensitive than amplification based on 529-bp RE sequence (Chemoh et al., 2016). In another survey of $T$. gondii oocysts presence in cat feces using PCR assays targeting 529-bp RE sequence and B1 gene, the prevalence rate detected by PCR assay based on 529- bp RE sequence was 5.3\%, which was lower than the detection level obtained by B1gene-based assay (17.95\%). In our study, the concordance between the three PCR assays showed that PCR assay based on T. gondii 529-bp RE sequence or ITS-1 sequence can detect

304

305

306

307

308

309

310

311

312

313

314

315

316

317

318

319

320

321

322

323

324

325

326

327

328

329 more positive samples than PCR assay based on B1 gene sequence. There are likely to be inhibitors within soil (e.g. humic acid), which can alter PCR performance, however in this study we did not use an internal control to monitor any inhibition.

We were also interested in defining the genetic diversity of the amplified $T$. gondii DNA from the soil samples because understanding the genetic population structure of $T$. gondii in soil samples can have epidemiological and public health relevance. Interestingly, PCR-RFLP analysis revealed only one ToxoDB\#9 genotype in all analyzed PCR products. This result provides further support to previously reported finding where more than half of the examined T. gondii isolates in China were found to belong to genotype ToxoDB\#9, which is the most predominant genotype detected in all examined hosts (Pan et al., 2017).

\section{Conclusion}

This work shows that $T$. gondii DNA is widely distributed in soil samples collected from schools, parks, farms and coastal beaches in six geographic regions in China. The performance of PCR assays based on 529-bp RE sequence and ITS-1 sequence for the detection of T. gondii DNA was better than that of the B1 gene-based PCR assay. ToxoDB\#9 was the only genotype detected in the examined soil samples in China. The prevalence of soil contamination with $T$. gondii DNA varied by the level of sampling season, climatic feature, geographic region, and soil type. Implementation of measures to manage the risk of oocysts derived from cats may reduce soil contamination with $T$. gondii oocysts. More studies are warranted including more sensitive detection methods and sampling of cats for $T$. gondii with rigorous field work characterizing the ecology, movement, and behavior of potential wild felids. Our work provides baseline data to further risk assessment of $T$. gondii oocysts' contamination in Chinese soil. Future studies should explore the state of sporulation, viability and infectivity of the isolated oocysts. 


\section{Funding}

This work was funded by National Natural Science Foundation of China (Grant No. 31702383), by the State Key Laboratory of Veterinary Etiological Biology, Lanzhou Veterinary Research Institute, Chinese Academy of Agricultural Sciences (Grant No. SKLVEB2017KFKT007), by China Postdoctoral Science Foundation (Grant No. 2016M602145), and by the Fundamental Research Funds of Chinese Academy of Agricultural Sciences (Grant No. Y2016JC05).

\section{Declaration of competing interest}

All authors have no conflict of interest to declare.

\section{References}

Afonso, E., Lemoine, M., Poulle, M.L., Ravat, M.C., Romand, S., Thulliez, P., et al., 2008. Spatial distribution of soil contamination by Toxoplasma gondii in relation to cat defecation behaviour in an urban area. Int. J. Parasitol. 38, 1017-1023.

Alvarado-Esquivel, C., Liesenfeld, O., Márquez-Conde, J.A., Estrada-Martínez, S., Dubey, J.P., 2010. Seroepidemiology of infection with Toxoplasma gondii in workers occupationally exposed to water, sewage, and soil in Durango, Mexico. J. Parasitol. 96, 847850 .

Burrells, A., Bartley, P.M., Zimmer, I.A., Roy, S., Kitchener, A.C., Meredith, A., et al., 2013. Evidence of the three main clonal Toxoplasma gondii lineages from wild mammalian carnivores in the UK. Parasitology 140, 1768-1776.

Chemoh, W., Sawangjaroen, N., Nissapatorn, V., Sarmwittayawon, N., 2016. Molecular investigation on the occurrence of Toxoplasma gondii oocysts in cat faeces using TOXelement and ITS-1 region targets. Vet. J. 215, 118-122.

Cong, W., Liu, G.H., Meng, Q.F., Dong, W., Qin, S.Y., Zhang, F.K., et al., 2015. Toxoplasma gondii infection in cancer patients: prevalence, risk factors, genotypes and association with clinical diagnosis. Cancer Lett. 359, 307-313.

Cong, W., Zhang, N.Z., Hou, J.L., Wang, X.C., Ma, J.G., Zhu, X.Q., et al., 2017. First detection and genetic characterization of Toxoplasma gondii in market-sold oysters in China. Infect. Genet. Evol. 54, 276-278.

Coutinho, S.G., Lobo, R., Dutra, G., 1982. Isolation of Toxoplasma from the soil during an outbreak of toxoplasmosis in a rural area in Brazil. J. Parasitol. 68, 866-868.

Dabritz, H.A., Conrad, P.A., 2010. Cats and Toxoplasma: implications for public health. Zoonoses. Public. Health 57, 34-52.

Dos Santos, T.R., Nunes, C.M., Luvizotto, M.C., de Moura, A.B., Lopes, W.D., da Costa, A.J., et al., 2010. Detection of Toxoplasma gondii oocysts in environmental samples from public schools. Vet. Parasitol. 171, 53-57.

Dubey, J.P., 2010. Toxoplasmosis of Animals and Humans. CRC Press Inc, Boca Raton, FL.

Dubey, J.P., Beattie, C.P., 2010. Toxoplasmosis of Animals and Humans, second ed. CRC Press Inc, Boca Raton, Florida, pp. 1-313.

Du, F., Feng, H.L., Nie, H., Tu, P., Zhang, Q.L., Hu, M., et al., 2012. Survey on the contamination of Toxoplasma gondii oocysts in the soil of public parks of Wuhan, China.

Vet. Parasitol. 184, 141-146.

Dumètre, A., Dardé, M.L., 2003. How to detect Toxoplasma gondii oocysts in environ-mental samples? FEMS. Microbiol. 27, 651-661.

Frenkel, J.K., Dubey, J.P., Miller, N.L., 1970. Toxoplasma gondii in cats: fecal stages identified as coccidian oocysts. Science 167, 893-896.Gagelidze, N.A., Amiranashvili, L.L., Sadunishvili, T.A., Kvesitadze, G.I., Urushadze, T.F., 
Kvrivishvili, T.O., 2018. Bacterial composition of different types of soils of Georgia. Ann. Agric. Sci. (Cairo) 16, 17-21.

Gotteland, C., Gilot-Fromont, E., Aubert, D., Poulle, M.L., Dupuis, E., Dardé, M.L., et al., 2014. Spatial distribution of Toxoplasma gondii oocysts in soil in a rural area: influence of cats and land use. Vet. Parasitol. 205, 629-637.

Homan, W.L., Vercammen, M., De Braekeleer, J., Verschueren, H., 2000. Identification of a 200- to 300-fold repetitive $529 \mathrm{bp}$ DNA fragment in Toxoplasma gondii, and its use for diagnostic and quantitative PCR. Int. J. Parasitol. 30, 69-75.

Jones, C.D., Okhravi, N., Adamson, P., Tasker, S., Lightman, S., 2000. Comparison of PCR detection methods for B1, P30, and 18S rDNA genes of $T$. gondii in aqueous humor. Invest. Ophthalmol. Vis. Sci. 41, 634-644.

Jones, J.L., Dargelas, V., Roberts, J., Press, C., Remington, J.S., Montoya, J.G., 2009. Risk factors for Toxoplasma gondii infection in the United States. Clin. Infect. Dis. 49, 878884.

Jones, J.L., Dubey, J.P., 2010. Waterborne toxoplasmosis-recent developments. Exp. Parasitol. $124,10-25$.

Jones, K.E., Patel, N.G., Levy, M.A., Storeygard, A., Balk, D., Gittleman, J.L., et al., 2008. Global trends in emerging infectious diseases. Nature 451, 990-993.

Lass, A., Pietkiewicz, H., Modzelewska, E., Dumètre, A., Szostakowska, B., Myjak, P., 2009. Detection of Toxoplasma gondii oocysts in environmental soil samples using molecular methods. Eur. J. Clin. Microbiol. Infect. Dis. 28, 599-605.

Lélu, M., Villena, I., Dardé, M.L., Aubert, D., Geers, R., Dupuis, E., et al., 2012. Quantitative estimation of the viability of Toxoplasma gondii oocysts in soil. Appl. Environ. Microbiol. $78,5127-5132$.

Lindsay, D.S., Dubey, J.P., 2009. Long-term survival of Toxoplasma gondii sporulated oocysts in seawater. J. Parasitol. 95, 1019-1020.

Liu, X.C., He, Y., Han, D.G., Zhang, Z.C., Li, K., Wang, S., et al., 2017. Detection of Toxoplasma gondii in chicken and soil of chicken farms in Nanjing region, China. Infect. Dis. Poverty. 6, 62.

Li, Y.N., Nie, X., Peng, Q.Y., Mu, X.Q., Zhang, M., Tian, M.Y., et al., 2015. Seroprevalence and genotype of Toxoplasma gondii in pigs, dogs and cats from Guizhou province, Southwest China. Parasites Vectors 8, 214.

Mancianti, F., Nardoni, S., Mugnaini, L., Guerrini, A., Gazzola, V., Papini, R.A., 2015. A retrospective molecular study of select intestinal protozoa in healthy pet cats from Italy. J. Feline Med. Surg. 17, 163-167.

Meerburg, B.G., Kijlstra, A., 2009. Changing climate-changing pathogens: Toxoplasma gondii in north-western europe. Parasitol. Res. 105, 17-24.

Montoya, J.G., Liesenfeld, O., 2004. Toxoplasmosis. Lancet. 363, 1965-1976. Pan, M., Lyu, C., Zhao, J., Shen, B., 2017. Sixty years (1957-2017) of research on toxoplasmosis in China-an overview. Front. Microbiol. 8, 1825.

R Development Core Team, 2011. R: a Language and Environment for Statistical Computing. R Foundation for Statistical Computing, Vienna, Austria. http://www.R-project.org.

Robert-Gangneux, F., Dardé, M.L., 2012. Epidemiology of and diagnostic strategies for toxoplasmosis. Clin. Microbiol. Rev. 25, 264-296.

Salant, H., Marcovics, A., Spira, D.T., Hamburger, J., 2007. The development of a molecular approach for coprodiagnosis of Toxoplasma gondii. Vet. Parasitol. 146, 214-220.

Salant, H., Spira, D., Hamburger, J., 2010. A comparative analysis of coprologic diagnostic methods for detection of Toxoplasma gondii in cats. Am. J. Trop. Med. Hyg. 82, 865-870.

Shapiro, K., Conrad, P.A., Mazet, J.A., Wallender, W.W., Miller, W.A., Largier, J.L., 2010. Effect of estuarine wetland degradation on transport of Toxoplasma gondii surrogates 
from land to sea. Appl. Environ. Microbiol. 76, 6821-6828. Simon, A., Bigras Poulin, M., Rousseau, A.N., Dubey, J.P., Ogden, N.H., 2013a. in western Québec, Canada. J. Wildl. Dis. 49, 39-48. Simon, A., Poulin, M.B., Rousseau, A.N., Ogden, N.H., 2013b. Fate and transport of Toxoplasma gondii oocysts in seasonally snow covered watersheds: a conceptual framework from a melting snow pack to the Canadian arctic coasts. Int. J. Environ. Res. Public Health 10, 994-1005.

Simon, J.A., Kurdzielewicz, S., Jeanniot, E., Dupuis, E., Marnef, F., Aubert, D., et al., 2017. Spatial distribution of soil contaminated with Toxoplasma gondii oocysts in relation to the distribution and use of domestic cat defecation sites on dairy farms. Int. J. Parasitol. 47, 357-367.

Stagno, S., Dykes, A.C., Amos, C.S., Head, R.A., Juranek, D.D., Walls, K., 1980. An out- break of toxoplasmosis linked to cats. Pediatrics 65, 706-712.

VanWormer, E., Carpenter, T.E., Singh, P., Shapiro, K., Wallender, W.W., Conrad, P.A., et al., 2016. Coastal development and precipitation drive pathogen flow from land to sea: evidence from a Toxoplasma gondii and felid host system. Sci. Rep. 6, 29252.

Venables, W.N., Ripley, B.D., 2002. Modern Applied Statistics with S, fourth ed. Springer, New York.

Wang, M., Meng, P., Ye, Q., Pu, Y.H., Yang, X.Y., Luo, J.X., et al., 2014. Detection of Toxoplasma gondii oocysts in soils in northwestern China using a new semi-nested PCR assay. BMC Vet. Res. 10, 238. 
461 Table 1 Frequency of Toxoplasma gondii oocysts in 2,100 soil samples.

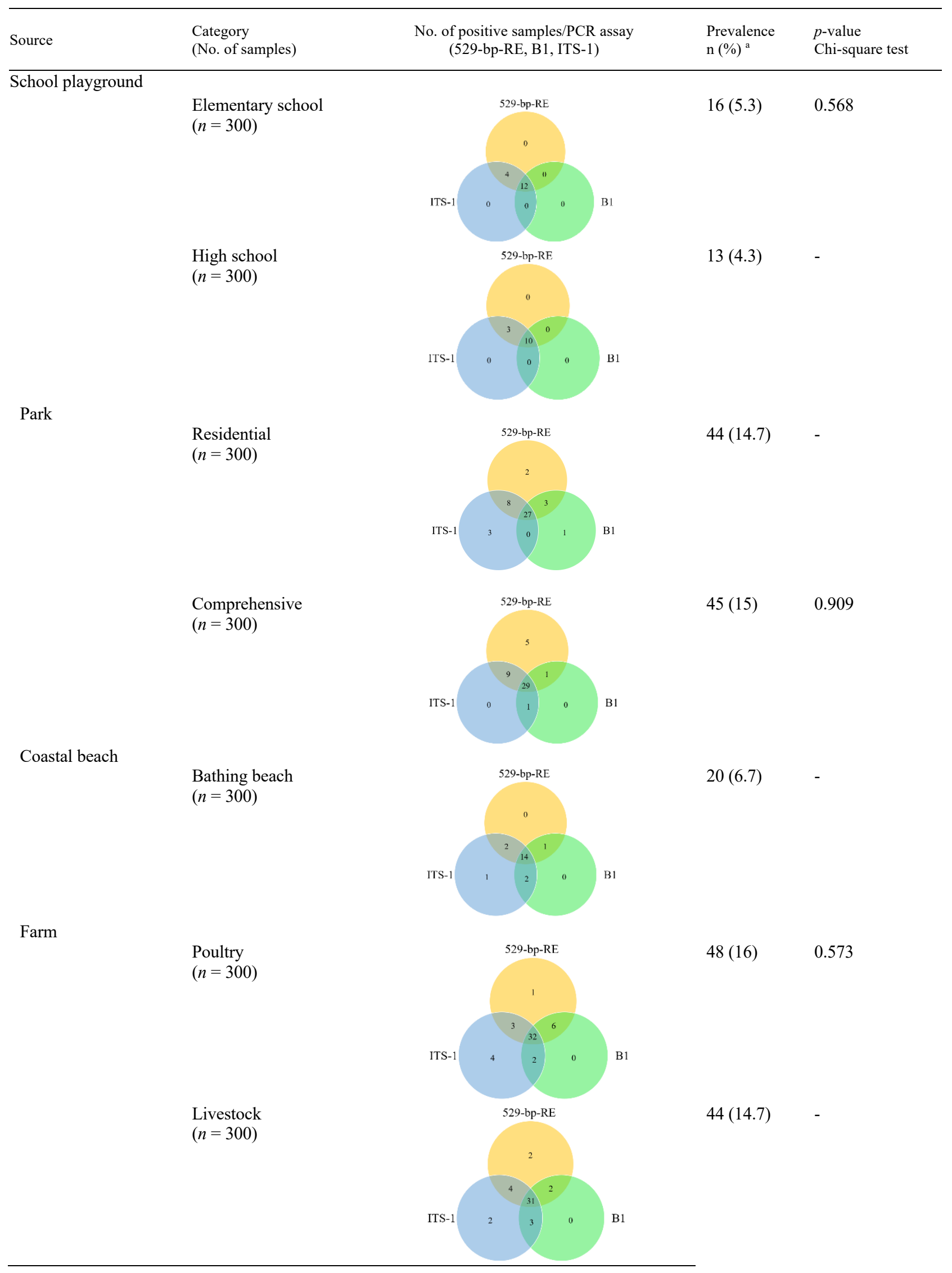


$n=2,100$

529-bp-RE

462

${ }^{\mathrm{a}}$ The prevalence values (presented inside parentheses) are the number of positive samples out of total number of samples

463 analyzed per category.

464 
Table 2. Prevalence of Toxoplasma gondii DNA in 420 sampling sites.

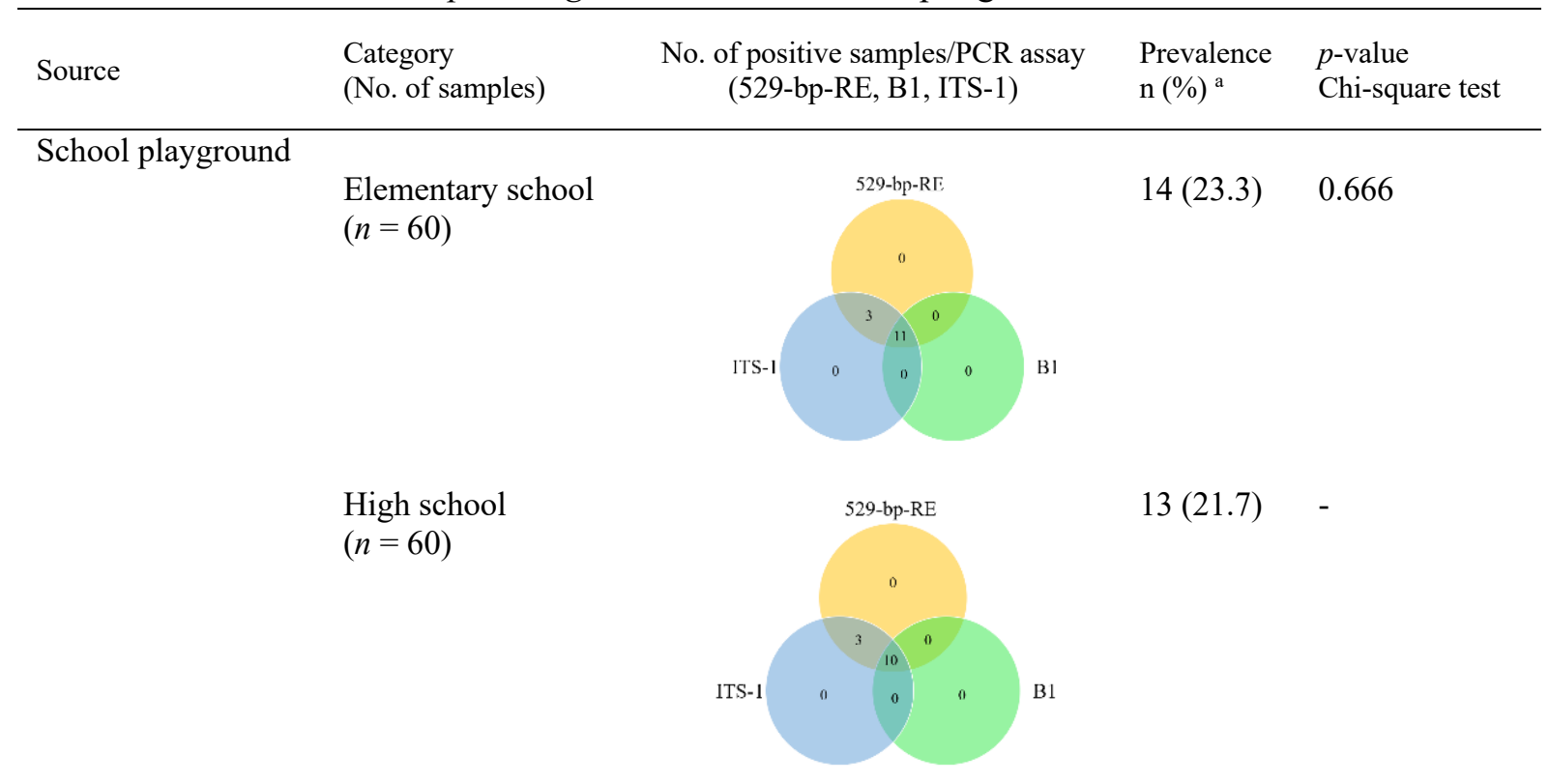

Park

$$
\begin{aligned}
& \text { Residential } \\
& (n=60)
\end{aligned}
$$

Comprehensive $(n=60)$

Bathing beach $(n=60)$

$$
\text { Poultry }
$$$$
(n=60)
$$

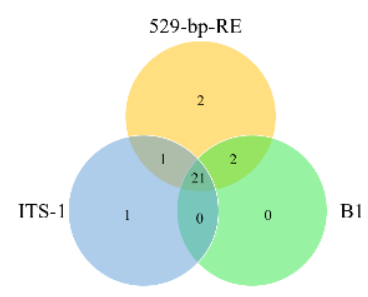

$27(55) \quad 0.273$

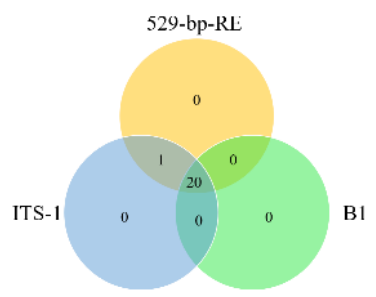

$21(35)$

12 (20)
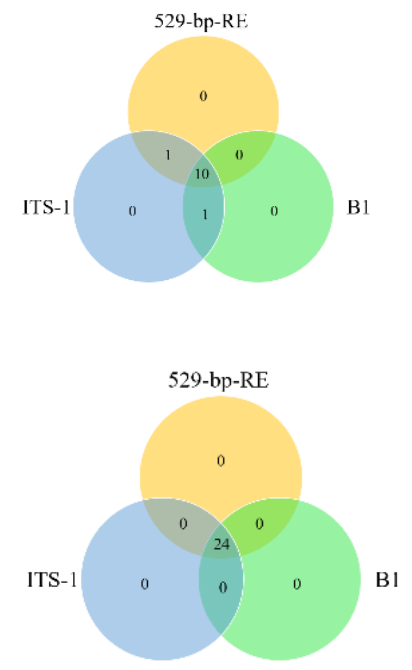

$24(40) \quad 0.201$ 


\section{Livestock}

$(n=60)$

Total

$n=420$

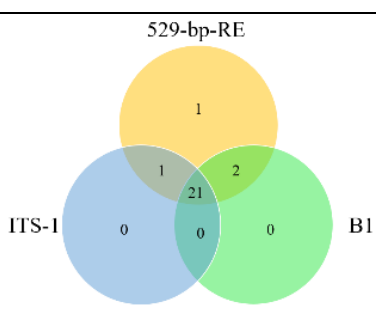

529-bp-RE

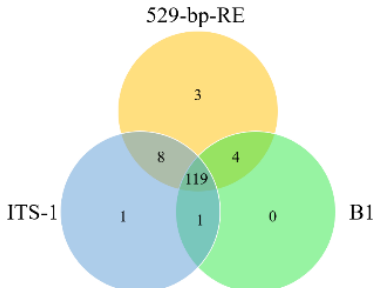

$25(41.6)$

$136(32.3)$

$\overline{{ }^{a}}$ The prevalence values (presented inside parentheses) are the number of positive samples out of total number of 466 samples analyzed per category. 
468 Table 3 Parameter estimates and odds ratios obtained from the multiple logistic regression 469 model. The odds ratios presented for each remaining risk factor represent the odds ratio relative 470 to the reference level (source coastal beach) due to exposure to the factor.

471

\begin{tabular}{lllll}
\hline Coefficient & Estimate & Standard error & Odds ratio $(95 \% \mathrm{CI})$ & $p$-value \\
\hline Intercept & -4.007 & 0.337 & - & 0.000 \\
\hline Source farm & 1.130 & 0.362 & $3.10(1.52-6.29)$ & 0.002 \\
\hline Source park & 0.953 & 0.362 & $2.59(1.28-5.27)$ & 0.009 \\
\hline Source school & 0.066 & 0.384 & $1.07(0.50-2.27)$ & 0.864 \\
\hline
\end{tabular}

472 
Table 4

474 Genotyping of Toxoplasma gondii DNA in various soil sources in China.

475

\begin{tabular}{|c|c|c|c|c|c|c|c|c|c|c|c|c|c|c|}
\hline Isolate ID & Host/source & Location & SAG1 & $\begin{array}{l}5^{\prime}+3 ' \\
\text { SAG2 }\end{array}$ & $\begin{array}{l}\text { Alt. } \\
\text { SAG2 }\end{array}$ & SAG3 & BTUB & GRA6 & $\mathrm{c} 22-8$ & $\mathrm{c} 29-2$ & L358 & PK1 & Apico & Genotype \\
\hline GT1 & Goat & United States & $\mathrm{I}$ & $\mathrm{I}$ & $\mathrm{I}$ & $\mathrm{I}$ & $\mathrm{I}$ & $\mathrm{I}$ & $\mathrm{I}$ & $\mathrm{I}$ & $\mathrm{I}$ & $\mathrm{I}$ & $\mathrm{I}$ & Reference, Type I, ToxoDB \#10 \\
\hline PTG & Sheep & United States & II/III & II & II & II & II & II & II & II & II & II & II & Reference, Type II, ToxoDB \#1 \\
\hline CTG & Cat & United States & $\mathrm{II} / \mathrm{III}$ & III & III & III & III & III & III & III & III & III & III & Reference, Type III, ToxoDB \#2 \\
\hline MAS & Human & France & $\mathrm{u}-1$ & I & II & III & III & III & $\mathrm{u}-1^{\mathrm{a}}$ & I & I & III & I & Reference, ToxoDB \#17 \\
\hline $\mathrm{TgCgCa}$ & Cougar & Canada & I & II & II & III & II & II & II & $\mathrm{u}-1^{\mathrm{a}}$ & I & $\mathrm{u}-2^{\mathrm{a}}$ & I & Reference, ToxoDB \#66 \\
\hline TgCatBr5 & Cat & Brazil & I & III & III & III & III & III & I & I & I & $\mathrm{u}-1^{\mathrm{a}}$ & I & Reference, ToxoDB \#19 \\
\hline $\operatorname{TgWtdSc} 40$ & White-tailed deer & USA & $\mathrm{u}-1$ & II & II & II & II & II & II & II & I & II & I & Reference, ToxoDB \#5 \\
\hline TgCatBr64 & Cat & Brazil & I & I & $\mathrm{u}-1$ & III & III & III & $\mathrm{u}-1^{\mathrm{a}}$ & I & III & III & I & Reference, ToxoDB \#111 \\
\hline TgToucan & Toucan & Costa Rica & $\mathrm{u}-1$ & I & II & III & I & III & $\mathrm{u}-2^{\mathrm{a}}$ & I & I & III & I & Reference, ToxoDB \#52 \\
\hline TgS1 & Soil & Shandong & $\mathrm{u}-1$ & II & II & III & III & II & II & III & II & II & I & ToxoDB \#9 \\
\hline $\mathrm{TgS} 2$ & Soil & Shandong & $\mathrm{u}-1$ & II & II & III & III & II & II & III & II & II & I & ToxoDB \#9 \\
\hline TgS3 & Soil & Henan & $\mathrm{u}-1$ & II & II & III & III & II & II & III & II & II & I & ToxoDB \#9 \\
\hline TgS4 & Soil & Henan & $\mathrm{u}-1$ & II & II & III & III & II & II & III & II & II & I & ToxoDB \#9 \\
\hline TgS5 & Soil & Jilin & $\mathrm{u}-1$ & II & II & III & III & II & II & III & II & II & I & ToxoDB \#9 \\
\hline TgS6 & Soil & Yunnan & $\mathrm{u}-1$ & II & II & III & III & II & II & III & II & II & I & ToxoDB \#9 \\
\hline TgS7 & Soil & Guangdong & $\mathrm{u}-1$ & II & II & III & III & II & II & III & II & II & I & ToxoDB \#9 \\
\hline TgS8 & Soil & Gansu & $\mathrm{u}-1$ & II & II & III & nd & II & II & III & II & II & I & ToxoDB \#9 \\
\hline TgS9 & Soil & Gansu & $\mathrm{u}-1$ & II & II & III & III & II & II & III & II & II & nd & ToxoDB \#9 \\
\hline $\operatorname{TgS} 10$ & Soil & Shandong & $\mathrm{u}-1$ & II & II & III & III & II & II & III & II & II & nd & ToxoDB \#9 \\
\hline $\operatorname{TgS} 11$ & Soil & Gansu & $\mathrm{Nd}$ & II & II & III & III & II & $\mathrm{Nd}$ & III & I & II & I & ToxoDB \#9 \\
\hline $\mathrm{TgS} 12$ & Soil & Guangdong & $\mathrm{Nd}$ & II & II & III & III & II & II & III & II & nd & I & ToxoDB \#9 \\
\hline $\operatorname{TgS} 13$ & Soil & Henan & $\mathrm{u}-1$ & II & II & III & III & nd & II & III & II & II & nd & ToxoDB \#9 \\
\hline TgS14 & Soil & Jilin & $\mathrm{u}-1$ & II & II & III & III & II & II & III & II & nd & nd & ToxoDB \#9 \\
\hline $\operatorname{TgS} 15$ & Soil & Yunnan & $\mathrm{u}-1$ & II & II & III & III & II & nd & nd & II & nd & nd & - \\
\hline
\end{tabular}

$477 \mathrm{u}-1$ and $\mathrm{u}-2$ denote novelRFLP genotypes.

478 nd: no data 


\section{Additional files}

Additional file 1: Fig. S1. Venn diagram showing the unique and shared positive results obtained by the three PCR assays based on 529-bp-RE, B1 and ITS-1 nucleotide sequences for detection of T. gondii DNA in soil samples.

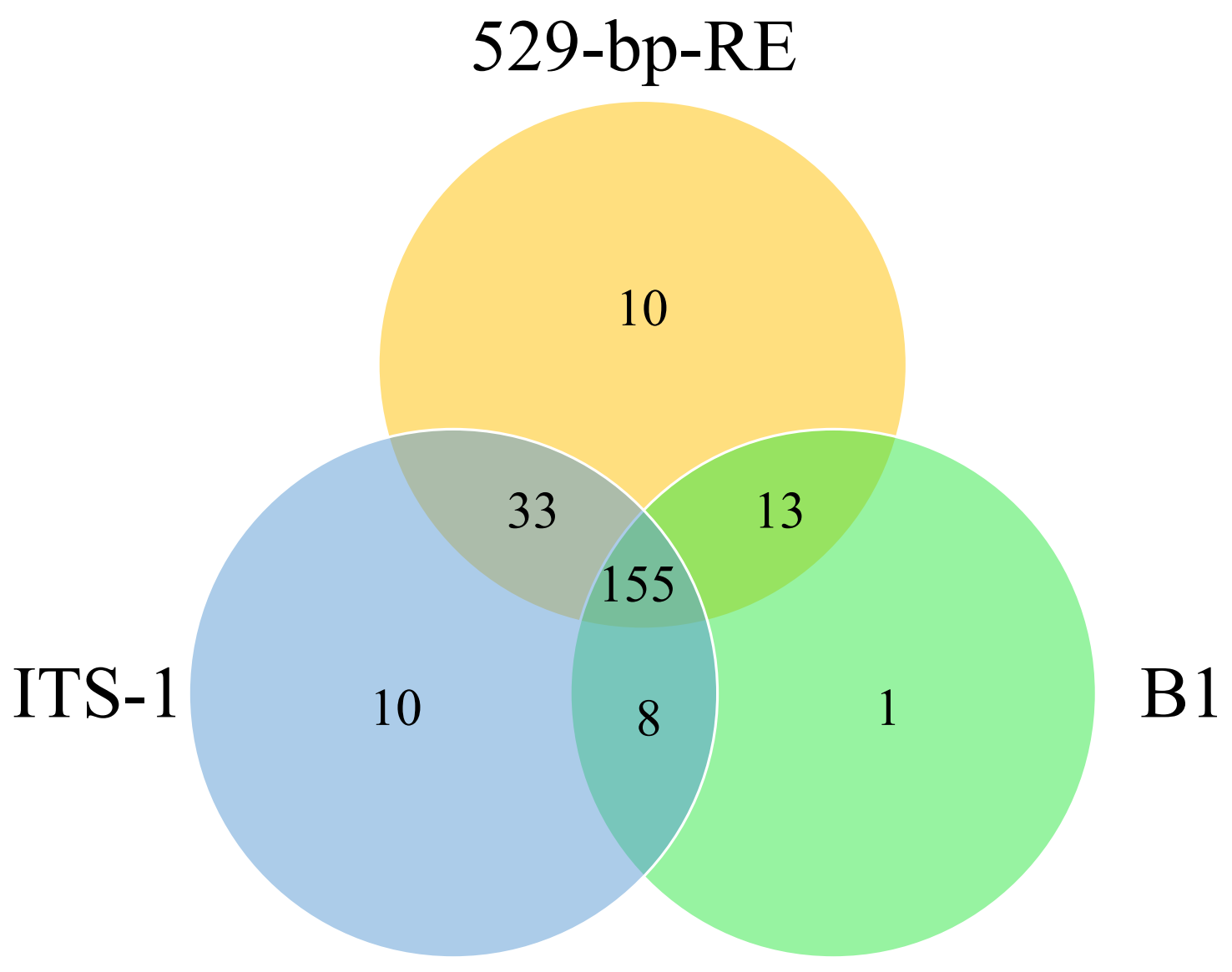


Additional file 2: Table S1: Primers used in the PCR assays.

\begin{tabular}{|c|c|c|c|c|}
\hline Method & Target & Nucleotide sequence (5'-3') & Amplicon & Reference \\
\hline $\begin{array}{l}\text { Conventional } \\
\text { PCR }\end{array}$ & 529 bp-RE & $\begin{array}{l}\text { TOX4- } \\
\text { CGCTGCAGGGAGGAAGACGAAAGTTG } \\
\text { TOX5-CGCTGCAGACAGAGTGCATCTGGATT }\end{array}$ & $529 \mathrm{bp}$ & (Lélu et al., 2012) \\
\hline Semi-nested PCR & B1 & $\begin{array}{l}\text { TOXO1- GGAACTGCATCCGTTCATGAG } \\
\text { TOXO2-TCTTTAAAGGGTTCGTGGTC } \\
\text { TOXO4-TGCATAGGTTGCAGTCACTG }\end{array}$ & $98 \mathrm{bp}$ & (Homan et al., 2000) \\
\hline Nested PCR & ITS-1 & $\begin{array}{l}\text { Tg-NN1- TCAACCTTTGAATCCAAA } \\
\text { Tg-NN2- CGAGCCAAGACATCCATT } \\
\text { Tg-NP1- GTGATAGTATCGAAAGGTAT } \\
\text { Tg-NP2- ACTCTCTCTCAAATGTTCCT }\end{array}$ & $227 b p$ & (Jones et al., 2000) \\
\hline
\end{tabular}


Additional file 3: Table S2: Primers used in the Mutiplex PCR-based genotyping of $T$. gondii strains.

\begin{tabular}{|c|c|c|c|}
\hline Primer IDs & Primer sequence (5'-3') & Loci & Size (bp) \\
\hline SAG1-Fext & GTTCTAACCACGCACCCTGAG & \multirow{2}{*}{ SAG1 } & \multirow{2}{*}{503} \\
\hline SAG1-Rext2 & AAGAGTGGGAGGCTCTGTGA & & \\
\hline 5SAG2-Fext & GCTACCTCGAACAGGAACAC & \multirow{2}{*}{ 5'-SAG2 } & \multirow{2}{*}{334} \\
\hline 5SAG2-Rext & GCATCAACAGTCTTCGTTGC & & \\
\hline 3SAG2-Fext & TCTGTTCTCCGAAGTGACTCC & \multirow{2}{*}{ 3'-SAG2 } & \multirow{2}{*}{327} \\
\hline 3SAG2-Rext & TCAAAGCGTGCATTATCGC & & \\
\hline P43S1 & CAАСТСТСАССАТТССАССС & \multirow{2}{*}{ SAG3 } & \multirow{2}{*}{311} \\
\hline P43AS1 & GCGCGTTGTTAGACAAGACA & & \\
\hline Btb $(e x t) F$ & TCCAAAATGAGAGAAATCGT & \multirow{2}{*}{ BTUB } & \multirow{2}{*}{529} \\
\hline Btb $(e x t) R$ & AAATTGAAATGACGGAAGAA & & \\
\hline GRA6-F1x & ATTTGTGTTTCCGAGCAGGT & \multirow{2}{*}{ GRA6 } & \multirow{2}{*}{546} \\
\hline GRA6-R1 & GCACCTTCGCTTGTGGTT & & \\
\hline c22-8Fext & TGATGCATCCATGCGTTTAT & \multirow{2}{*}{$\mathrm{c} 22-8$} & \multirow{2}{*}{657} \\
\hline c22-8Rext & ССТCCACTTCTTCGGTCTCA & & \\
\hline c29-2Fext & ACCCACTGAGCGAAAAGAAA & \multirow{2}{*}{ c29-2 } & \multirow{2}{*}{689} \\
\hline c29-2Rext & AGGGTCTCTTGCGCATACAT & & \\
\hline L358-Fext & TCTCTCGACTTCGCCTCTTC & \multirow{2}{*}{ L358 } & \multirow{2}{*}{690} \\
\hline L358-Rext & GCAATTTCCTCGAAGACAGG & & \\
\hline PK1-Fext & GAAAGCTGTCCACCCTGAAA & \multirow{2}{*}{ PK1 } & \multirow{2}{*}{1027} \\
\hline PK1-Rext & AGAAAGCTCCGTGCAGTGAT & & \\
\hline SAG2-Fext & GGAACGCGAACAATGAGTTT & \multirow{2}{*}{ SAG2 } & \multirow{2}{*}{729} \\
\hline SAG2-Rext: & GCACTGTTGTCCAGGGTTTT & & \\
\hline Apico-Fext: & TGGTTTTAACCCTAGATTGTGG & \multirow{2}{*}{ Apico } & \multirow{2}{*}{846} \\
\hline Apico-Rext: & AAACGGAATTAATGAGATTTGAA & & \\
\hline
\end{tabular}


Additional file 4: Table S3: Primers used in the nested PCR-based genotyping of T. gondii strains.

\begin{tabular}{|c|c|c|c|}
\hline Primer IDs & Primer sequences $\left(5^{\prime}-3^{\prime}\right)$ & Loci. & Size (bp) \\
\hline $\mathrm{SAG} 1-\mathrm{S} 2$ & CAATGTGCACCTGTAGGAAGC & \multirow{2}{*}{ SAG1 } & \multirow{2}{*}{390} \\
\hline SAG1-Rext & GTGGTTCTCCGTCGGTGTGAG & & \\
\hline 5-SAG2F & GAAATGTTTCAGGTTGCTGC & \multirow[t]{2}{*}{ 5'-SAG2 } & \multirow{2}{*}{242} \\
\hline 5-SAG2R & GCAAGAGCGAACTTGAACAC & & \\
\hline 3-SAG2F & ATTCTCATGCCTCCGCTTC & \multirow[t]{2}{*}{ 3'-SAG2 } & \multirow{2}{*}{222} \\
\hline 3-SAG2R & AACGTTTCACGAAGGCACAC & & \\
\hline $\mathrm{P} 43 \mathrm{~S} 2$ & TCTTGTCGGGTGTTCACTCA & \multirow{2}{*}{ SAG3 } & \multirow{2}{*}{225} \\
\hline P43AS2 & CACAAGGAGACCGAGAAGGA & & \\
\hline Btb-F & GAGGTCATCTCGGACGAACA & \multirow{2}{*}{ Btub } & \multirow{2}{*}{411} \\
\hline Btb-R & TTGTAGGAACACCCGGACGC & & \\
\hline GRA6-F1 & TTTCCGAGCAGGTGACCT & \multirow{2}{*}{ GRA6 } & \multirow{2}{*}{344} \\
\hline GRA6-R1x & TCGCCGAAGAGTTGACATAG & & \\
\hline SAG2-Fa & ACCCATCTGCGAAGAAAACG & \multirow{2}{*}{ SAG2 } & \multirow{2}{*}{546} \\
\hline SAG2-Ra & ATTTCGACCAGCGGGAGCAC & & \\
\hline L358-F2 & AGGAGGCGTAGCGCAAGT & \multirow{2}{*}{ L358 } & \multirow{2}{*}{418} \\
\hline L358-R2 & CCCTCTGGCTGCAGTGCT & & \\
\hline PK1-F & CGCAAAGGGAGACAATCAGT & \multirow{2}{*}{ PK1 } & \multirow{2}{*}{903} \\
\hline PK1-R & TCATCGCTGAATCTCATTGC & & \\
\hline $\mathrm{c} 22-8 \mathrm{~F}$ & TCTCTCTACGTGGACGCC & \multirow{2}{*}{$\mathrm{c} 22-8$} & \multirow{2}{*}{521} \\
\hline $\mathrm{c} 22-8 \mathrm{R}$ & AGGTGCTTGGATATTCGC & & \\
\hline $\mathrm{c} 29-2 \mathrm{~F}$ & AGTTCTGCAGAGTGTCGC & \multirow{2}{*}{$\mathrm{c} 29-2$} & \multirow{2}{*}{446} \\
\hline c29-2R & TGTCTAGGAAAGAGGCGC & & \\
\hline Apico-F & TGCAAATTCTTGAATTCTCAGTT & \multirow{2}{*}{ Apico } & \multirow{2}{*}{640} \\
\hline Apico-R & GGGATTCGAACCCTTGATA & & \\
\hline
\end{tabular}


Additional file 5: Table S4: Univariate logistic regression analysis of risk factors for the presence of T. gondii oocysts in soil samples in China based on the three PCR assays used in the present study.

\begin{tabular}{|c|c|c|c|}
\hline Risk factors & $\begin{array}{l}\text { Prevalence } \\
\text { Positive/total (\%) }\end{array}$ & Odds ratio $(95 \% \mathrm{CI}) *$ & $p$-value \\
\hline \multicolumn{4}{|l|}{ Soil source } \\
\hline Coastal beach & $20 / 300(6.7)$ & $14.00(9.14-22.76)$ & $<2 \mathrm{e}-16 \dagger$ \\
\hline Farm & $93 / 600(15.5)$ & $0.38(0.22-0.63)$ & 0.000 \\
\hline Park & $89 / 600(14.8)$ & $0.41(0.24-0.66)$ & 0.000 \\
\hline School & $29 / 600(4.8)$ & $1.40(0.77-2.51)$ & 0.255 \\
\hline \multicolumn{4}{|l|}{ Region } \\
\hline Gansu & $32 / 300(10.7)$ & $8.37(5.90-12.31)$ & $<2 \mathrm{e}-16 \dagger$ \\
\hline Shandong & $54 / 600(9)$ & $1.20(0.75-1.90)$ & 0.423 \\
\hline Henan & $44 / 300(14.7)$ & $0.69(0.42-1.12)$ & 0.142 \\
\hline Jilin & $32 / 300(10.7)$ & $1.00(0.59-1.68)$ & 1.000 \\
\hline Guangdong & $31 / 300(10.3)$ & $1.03(0.61-1.75)$ & 0.894 \\
\hline Yunnan & $38 / 300(12.7)$ & $0.82(0.49-1.35)$ & 0.446 \\
\hline \multicolumn{4}{|l|}{ Season } \\
\hline Autumn & $71 / 450(15.8)$ & $5.81(4.51-7.61)$ & $<2 \mathrm{e}-16 \dagger$ \\
\hline Winter & $24 / 255(8.7)$ & $1.33(0.84-2.16)$ & 0.219 \\
\hline Spring & $44 / 485(9.1)$ & $1.72(1.15-2.59)$ & 0.008 \\
\hline Summer & $102 / 910(11.2)$ & $1.52(1.08-2.14)$ & 0.014 \\
\hline \multicolumn{4}{|l|}{ Soil type } \\
\hline Brown soil & $34 / 300(11.3)$ & $7.82(5.55-11.37)$ & $<2 \mathrm{e}-16 \dagger$ \\
\hline Yellow brown soil & $44 / 300(14.7)$ & $0.74(0.45-1.19)$ & 0.225 \\
\hline Dark brown forest soil & $17 / 160(10.6)$ & $1.07(0.58-2.03)$ & 0.817 \\
\hline Chernozem & $15 / 140(10.7)$ & $1.06(0.56-2.07)$ & 0.847 \\
\hline Fine sand & $8 / 150(5.3)$ & $2.26(1.07-5.38)$ & 0.043 \\
\hline Coarse sand & $12 / 150(8)$ & $1.46(0.75-3.04)$ & 0.273 \\
\hline Red soil & $38 / 300(12.7)$ & $0.88(0.53-1.44)$ & 0.615 \\
\hline Latosolic red soil & $31 / 300(10.3)$ & $1.10(0.66-1.86)$ & 0.693 \\
\hline Yellow cinnamon soil & $32 / 300(10.7)$ & $1.07(0.64-1.79)$ & 0.794 \\
\hline \multicolumn{4}{|l|}{ Climatic feature } \\
\hline Subtropical monsoon & $69 / 600(11.5)$ & $8.67(6.08-12.83)$ & $<2 \mathrm{e}-16 \dagger$ \\
\hline Continental Monsoon Climate & $32 / 300(10.7)$ & $0.96(0.57-1.62)$ & 0.894 \\
\hline Temperate monsoon & $32 / 300(10.7)$ & $0.96(0.57-1.62)$ & 0.894 \\
\hline Tropical monsoon & $38 / 300(12.7)$ & $0.79(0.47-1.31)$ & 0.371 \\
\hline Warm temperate monsoon & $54 / 600(9)$ & $1.16(0.72-1.84)$ & 0.519 \\
\hline
\end{tabular}


Warm to subtropical, humid to semi-

* OR: Odds ratio; 95\% CI: 95\% confidence interval

$\dagger$ Reference against which other categories are compared 